\title{
LA POÉTICA DE ARISTÓTELES DEL RENACIMIENTO AL INICIO DEL VIRREINATO \\ Alina Mendoza*
}

RESUMEN: Este texto formula algunas cuestiones y propuestas sobre la participación de filósofos y poetas árabes, de Alberti, el Concilio tridentino y el primer virrey americano; se procura gestar conciencia sobre la importancia de diferentes agentes en la recepción de la Poética aristotélica durante el Medioevo y el Renacimiento; finalmente, se considera nuestra coyuntura histórica como herederos de la cultura novohispana.

$$
\text { sose }
$$

ABSTRACT: In this article, we will formulate questions and suggestions about the participation of Arab philosophers and poets, Alberti, the Council of Trent, and the first American Viceroy all of whom promoted the importance of different elements in the reception of Aristotle's Poetics during Medieval times and the Renaissance. We will also analyze the historic circumstance of their contribution to New Spain culture.

Palabras clave: Aristóteles, Poética, Renacimiento, Virreinato, Concilio tridentino. KEY WORDS: Aristotle, Poetics, Renaissance, Viceroyalty, Council of Trent.

RECEPCIÓN: 30 de julio de 2013.

APROBACIÓN: 12 de septiembbre de 2013.

* FES-Acatlán, Programa de Humanidades, UNAM. 
CITAM Derechos Reservados.

La reproducción total o parcial de este artículo se podrá hacer si el ITAM otorga la autorización previamente por escrito. 


\section{LA POÉTICA DE ARISTÓTELES DEL RENACIMIENTO AL INICIO DEL VIRREINATO}

\section{$\mathrm{E}_{\text {n el terreno de la filosofía, ignorar }}$} que el tema de la modernidad y sus límites ha nutrido la discusión teórica en las últimas décadas es como estar fuera de lugar. Esto incide en nuestro tema en la medida en que el Renacimiento ha sido considerado comúnmente como el comienzo de este período histórico y, como tal, ha sido sometido a revisión. Mas precisemos cómo afecta esto al tratamiento del redescubrimiento y la valoración de una obra aristotélica entre los siglos XV y XVI.

Por principio sirve discernir que, a pesar de que el Renacimiento se entiende como un lapso determinado del devenir humano, acontecido en Europa occidental entre el mil cuatrocientos y el mil seiscientos aproximadamente, la conceptualización de este período, precisamente como un renacer, fue una labor historiográfica lógicamente posterior. Fue fruto del pensamiento decimonónico que, otorgándose la oportunidad de dar nombre a esta etapa, condicionó la comprensión ulterior de la misma como comienzo renovador y revitalizante. Al hacerlo, además, este pensamiento puso de relieve un afán manifiesto en la modernidad temprana, a saber, el de estrechar los vínculos con el pasado mediato, grecolatino. Con ello relegó a un segundo plano una necesidad quizá mayor del mismo momento, la de diferenciarse lo más posible del pretérito próximo medieval.

Así, puede decirse que, en la medida en que esta perspectiva del siglo diecinueve fungió como portavoz de los anhelos y pretensiones 
de la etapa que nos ocupa, se manifestó desinteresada por los aspectos comunes entre ella y el tiempo previo inmediato. El interés por relacionar tales momentos contiguos, en cambio, resulta propio de perspectivas más actuales, en tanto que el estatus de la contemporaneidad con respecto a la modernidad en general, tiende más bien a pensarse simultáneamente en términos de continuidad y diferencia, y pensar así lo medieval con respecto a lo renacentista puede considerarse como una proyección de semejante atenuación de fronteras.

Volviendo al tema central de esta reflexión, la recepción de la Poética en el Renacimiento, hay que notar que abordarlo en términos de continuidad parece especialmente pertinente, debido a la importancia incomparable que Aristóteles alcanzó al cabo de la Edad Media, tanto por vía árabe como gracias a la traducción directa del griego al latín que desde entonces se realizó de gran parte de su obra. Debería por eso extrañarnos apreciar que la atención que semejante cuestión ha recibido es más bien escasa.

Ameritan detenimiento las razones de esta falta de atención, como también lo requieren las diferencias y similitudes entre el aristotelismo escolástico y el humanista. A fin de profundizar al menos en un elemento de este espectro, me enfocaré sólo en la Poética. En la primera parte de este artículo recordaré algunos antecedentes del redescubrimiento de la teoría aristotélica de la creación artística; revisaré luego los momentos cruciales del proceso paulatino de ese redescubrimiento, desde las vísperas de la caída de Constantinopla hasta que este tratado incide sutilmente en el Concilio de Trento. Sobre la base anterior, al final, me ocuparé de las primeras incidencias indirectas del tratado aristotélico en nuestro contexto, en tanto este tema yace también descuidado y nos atañe de más cerca.

\section{Antecedentes medievales del redescubrimiento de la teoría aristotélica de la creación artística}

Hemos atisbado que en el nombre de la época en que se redescubre la Poética, "Renacimiento", se cifran connotaciones distintas de una idea de temporalidad marcada por hiatos y, por tanto, por cierto senti- 
do de terminación y reinicio. Observemos ahora que calificar de antemano la recepción renacentista del tratado aristotélico como un redescubrimiento implica justamente un hiato análogo, un lapso histórico de sustracción a los ejercicios hermenéuticos de lectura, traducción y glosa. Pero cobremos conciencia también de que, en este caso, lo problemático no es solamente la pérdida sino, además, el reencuentro de la obra.

Hasta cierto punto, esto se debe a que tal extravío se ha vuelto casi mítico, gracias al éxito y a la filmación de una novela de Umberto Eco, que recrea con cierta libertad algunos datos históricos en torno a esta hipótesis. La dificultad a la que hemos de referirnos es de diversa índole, aunque en ella encontramos también inmerso al italiano. Resolverla es, en todo caso, una empresa de conciencia colectiva en la que esta reflexión aspira a participar.

En una conferencia denominada Entre Averroes y Borges que data de hace diez años, el autor de El nombre de la rosa menciona algunos de los agentes fundamentales que participaron en el redescubrimiento de la teoría aristotélica de la creación artística, a partir de Averroes. Retomaré los primeros para observar la postura de Eco al respecto y continuar con el recuento.

En dicha conferencia se nos recuerda que el texto con el cual Averroes incide en el redescubrimiento data del año 1175 y no es una traducción, como indica su nombre: Comentario medio, ni se basa en una traducción directa del griego al árabe, sino en una versión siriaca de dos siglos antes, basada a su vez en una copia griega desconocida. Puesto que precisamente este texto árabe aportó las primeras noticias de la Poética en latín, gracias a que Hernán Alemán (m. 1272) lo tradujo a esta lengua ochenta y un años más tarde, el semiólogo y filósofo italiano insiste en que esas novedades ofrecieron una semblanza tan distorsionada del tratado aristotélico sobre poesía, por desconocimiento de la práctica dramática en el contexto árabe, que, en lugar de despertar interés por él, retardaron su valoración.

Por otra parte, a pesar de que varias obras de Aristóteles se habían hecho accesibles desde el siglo VI, gracias a que Beocio las tradujo 
directamente del griego, las de contenido antropológico comienzan a aparecer apenas en las vísperas del movimiento humanista; esto último deja entrever la magnitud y la prontitud del impacto que tuvo el reacceso a estas fuentes, a pesar de lo tardío. La Poética es de las últimas obras aristotélicas de tipo antropológico en aparecer, puesto que lo hace hasta 1278, mediada por la traducción de Guillermo de Moerbeke. Como el interés por el tratado siguió siendo casi nulo, a pesar de que también esta traducción fue hecha directamente del griego, Eco vuelve a preguntarse por la razón, atribuyendo todavía parte de la responsabilidad a la incidencia árabe previa en la historia de la recepción del texto; él supone, por un lado, que uno de los conceptos más afectados por la intervención arábiga en esta trayectoria es el de "tragedia" y, por otro, que la deformación que sufre esta noción llegó a tal grado que, cuando finalmente logró rescatarse en latín la idea griega original, no fue posible asociarla de inmediato con la representación dramática.

Ahora bien, al señalar nítidamente esta valoración negativa sostenida por Eco sobre el capítulo árabe del rencuentro de la Poética, no me propongo debatir puntualmente su argumentación. Observo, no obstante, que apenas un par de años después dicha conferencia, en un artículo sobre los antecedentes de la interpretación aviceniana de la Poética, ${ }^{1}$ un colega mexicano especialista en filosofía árabe, Xavier López-Farjeat, parte de premisas semejantes para identificar en cambio un rasgo positivo de la participación arábiga en la recepción del tratado griego sobre poesía. Tras la "infidelidad" o el distanciamiento frente a los planteamientos originales del texto aristotélico, él aprecia la participación de los traductores y comentaristas árabes del tratado en cuestión, en una tendencia colectiva a ampliar la comprensión de su propia tradición literaria. Por mi parte, ante esta diversidad de signo en la aproximación al problema, formulo un par de preguntas: ¿Acaso es claro que, en el encuentro con las fuentes, el propósito de ofrecer una comprensión cabal de lo planteado en ellas originalmente es mejor que procurar de inicio comprenderlas con base en y con miras al con-

${ }^{1}$ Luis Xavier López-Farjeat, “Antecedentes de la interpretación aviceniana de la Poética de Aristóteles”, Signos filosóficos, 2005, vol. 7, núm. 14, pp. 35-44. 
texto de uno? E independientemente de hasta qué punto es posible lo primero y evitable lo último, la segunda cuestión es si, a la larga, en su encuentro con la Poética, los renacentistas europeos no acabaron también sacrificando, a su manera, su incipiente vocación filológica en favor de un una aplicación de los contenidos de la fuente a los requerimientos de su propio contexto artístico y religioso.

Hablar, por ejemplo, de la presencia de elementos de la Poética en los tratados de León Batista Alberti y en el Concilio de Trento nos permitirá hilar una postura al respecto. Por ahora completemos la remembranza de los antecedentes arábigos del comentario de Averroes. Amerita la primera mención el cristiano Abu Bishr Matta (m. 940), a quien se atribuye la traducción de la Poética del siríaco al árabe, utilizada en el mencionado Comentario medio y efectuada hacia el 935. Le sigue Yahya Ibn Adi (893-974), discípulo del anterior e igualmente cristiano y traductor del tratado; en seguida se encuentran Al Kindi (801-873), Al Farabi (872-950) y Avicena (980-1030), quienes con base en los anteriores intercalan comentarios e interpretaciones del tratado en una o más de sus obras.

Para la comprensión del desvío de todos ellos del sentido primero de la Poética, López-Farjeat se remonta al impulso que recibió la literatura islámica con el establecimiento del Corán en siglo VIII. Por nuestra parte, veamos que, durante un lapso aproximado de dos siglos, en el ámbito medieval arábigo se registra un proceso constante de asimilación del tratado aristotélico de poesía, y que, al cabo de este tiempo, al pasar la llama al contexto europeo por vía de la escuela de traductores de Toledo, esa continuidad no se pierde, a pesar de los malos entendidos de fondo, sino que atraviesa hasta el Renacimiento tardío. Y es que, además de la versión latina ya mencionada del comentario de Averroes por parte de Hernán Alemán, en la misma escuela de Toledo, Miguel Escoto (1175-ca.1236) y Alfredo de Sareshel (ca.1180-1230) producen otras versiones a la misma obra arábiga. Incluso tras el advenimiento de la primera traducción directa de la Poética del griego al latín, versiones posteriores del comentario de Averroes continúan produciéndose, 
puesto que en pleno siglo XVI el médico de Paulo III, Jacob Ben Joseph Mantino de Tortosa (1490-1549), ofrece su propia versión. ${ }^{2}$

Por último, lo anterior adquiere mayor significación por el contraste implícito en el hecho, ya recordado por Eco, de que la primera traducción de la Poética del griego al latín permanece prácticamente ignorada. Aumenta el contraste tomar en cuenta, además, que esa traducción parece haber sido un encargo de Tomas de Aquino, más que una iniciativa propia de Moerbeke, aunque la muerte del teólogo sobrevino antes de que él pudiera ver consumada esa tarea; es bien conocida la influencia que la obra de este autor cristiano alcanzó desde entonces y a lo largo de todo el Renacimiento, alentando la prosecución del estudio de Aristóteles y ocupando en el siglo XVI un peso análogo al de los decretos papales.

Desde otro ángulo, agudiza el contraste el hecho de que la acogida de esa primera traducción haya sido tan fría que la segunda sólo se produjo más de dos siglos después. Y cuando finalmente ocurrió, su autor supuso que su nueva traducción era en realidad la primera.

\section{Momentos claves del redescubrimiento renacentista de la Poética}

La segunda traducción directa del griego al latín se produce, en 1498, de suerte que constituye ya una edición, propiamente, prístina o príncipe. Fue obra de Giorgio Valla (1447-1500), impresa en Venecia por Aldo Manuzio, quien a su vez publicó aparte, una década después, la primera edición en griego de este tratado.

Lógicamente, esto impulsó la realización de nuevas traducciones del griego al latín y, poco después, del griego a diversas lenguas modernas; estas nuevas traducciones suscitaron, por su parte y como en cascada, tanto la inclusión de múltiples comentarios, citas e interpretaciones de la Poética en diversas publicaciones, como la redacción de nuevos tratados de poética alusivos o contrarios al de Aristóteles. Así, esta segunda etapa comienza con la primera edición bilingüe (griego-latín) que, a pesar

${ }^{2}$ Marcelino Méndez y Pelayo, Obras completas, t. I, vols. I-III, Historia de las ideas estéticas en España, 2012, Santander-Cantabria, Ediciones Universidad Cantabria, p. 252. 
de distar casi dos décadas de la anterior, se reimprime una docena de veces en lo que resta del siglo y, en algunas de esas ocasiones, fuera ya de la península italiana. Alejandro Pazzi de Médicis (1483-1530) fue el autor de tal obra bilingüe y la misma imprenta aldina fue su cuna.

Hay que mencionar la traducción de Robortello (1516-1567), que data de 1548, por su competencia con la anterior en tanto nueva edición bilingüe y por la popularidad sin precedentes que alcanza; en las décadas siguientes se producen al menos dos traducciones del mismo tipo, es decir, con comentarios: la primera data de 1550 y amerita mención, en tanto ha sido considerada como precursora de las reglas que el movimiento contrareformista habría de exigir a las artes al término del Concilio de Trento, es decir, nueve años después. ${ }^{3}$ Esto es especialmente significativo dada la incidencia que dicho concilio tuvo, con apoyo del arte, en el amplio espectro de la formación de la conciencia novohispana.

Por razones semejantes y porque incrementó mucho el alcance y el reconocimiento del mismo tratado aristotélico, es importante incluir entre los momentos clave del redescubrimiento renacentista de la Poética el de la primera traducción del texto a una lengua romance. Vio la luz incluso un poco antes, en 1549, y por supuesto fue escrita en la lengua de Dante, la toscana. La realizó Bernardo Segni (1504-1558); así, al cabo de unos 20 años comenzaron a aparecer los primeros comentarios a la Poética en lengua vulgar, al lado de otros tratados sobre poesía, basados tanto en la misma obra aristotélica como en la Poética de Horacio. $\mathrm{Al}$ respecto, lo que a en nuestra ruta argumentativa conviene mencionar son las aportaciones de Marco Girolamo Vida (1489-1566), Sebastián Minturno (1500-1574) y Benedeto Varchi (1503-1565).

De estas últimas, las dos iniciales también ameritan mención por la participación de sus autores en el Concilio de Trento, puesto que los intereses comunes de ambos hacen más comprensible la presencia de elementos de la Poética en una de sus partes finales. No obstante, la publicación de la poética de Vida antecede por mucho el comienzo de la reunión tridentina (1527), y la redacción de la primera poética de Min-

${ }^{3}$ Cfr. María del Carmen Bobés, "Teoría de la comedia en la poética toscana", Revista de literatura, 2008, vol. LXX, núm. 140, pp. 371-404. 
turno (1559), puesto que este autor escribió dos, no se basa en el tratado griego; la segunda, en cambio, fue escrita el año que el concilio concluye incluyendo el famoso apartado sobre las imágenes sacras (1564); por tanto, permite suponer la intervención directa de su autor en esta clausura o, al menos, la de las determinaciones eclesiásticas recién asumidas en su concepción del arte literario. Algo análogo puede decirse de la obra posterior y más tardía de Vida, a pesar de que ya no versa sobre poesía, en la medida en que se aboca a difundir los principios de la Contrarreforma.

Por su parte, la importancia de la poética de Varchi, de 1553, conjuntamente con la de un rasgo aun no expresado de la de Segni, reside en que, por vía de artistas como Miguel Ángel y Tiziano, parece haber contribuido a una aplicación práctica de los aspectos de la Poética a la plástica que, además, resultaron reforzados y reflejados teóricamente en el mencionado cierre del Concilio tridentino. ${ }^{4}$

Hasta aquí, hemos destacado los aspectos mejor conocidos de la recepción de la Poética en el Renacimiento. No obstante, dada la insipiencia del reconocimiento de los tres restantes, cabe advertir su mérito a una atención mayor; así, cerraré esta parte explicando en qué sentido puede considerarse que el tratado aristotélico sustenta indirectamente el Concilio tridentino. Mas atendiendo el orden cronológico de su manifestación, comenzaré por hablar de las aportaciones de Manuel Crisoloras (1355-1415) y León Batista Alberti (1404-1472), que anteceden a la primera traducción renacentista de la Poética y allanan el terreno para que ella acontezca.

En su libro Giotto y los oradores,${ }^{5}$ Michael Baxandall observó hace un par de décadas que uno de los primeros maestros de griego en arribar al ámbito italiano renacentista como diplomático, Crisoloras, solía referirse a un fragmento en particular de la Poética contenido en el libro IV. Aunque este bizantino no escribió propiamente una obra en la que ello

${ }^{4}$ Véase Alina Mendoza Cantú, Nociones tridentinas y ecos aristotélicos en una Piedad de Buonarroti, 2010, México, tesis doctoral en Historia del arte, Universidad Nacional Autónoma de México, Facultad de Filosofía y Letras, pp. 34, 151 y 189.

${ }^{5}$ Michael Baxandall, Giotto and the Orators: Humanist Observers of Painting in Italy and the Discovery of Pictorial Composition (1350-1450), 1971, Oxford, Clarendon Press, pp. 80-2. 
conste, lo evidencian dos epístolas suyas y algunas alusiones de su discípulo principal, Guarino Veronese (1370-1460), y de su hijo.

Este pedagogo representa el primer eslabón de la apertura centro europea a la Poética, y se caracteriza por haber impreso a esta inauguración el interés por aplicar el tratado griego a las artes visuales. Así, de la cadena sutil que parte de él, derivan tanto el primer editor de la Poética como el primer traductor de esta obra, directamente del griego al latín, ambos ya mencionados, y el maestro de Miguel Ángel Buonarroti (1475-1564), Ángelo Poliziano (1454-1494): aquél, en tanto discípulo de Guarini; éste, por su sus vínculos familiares con otro discípulo de Crisoloras, Leonardo Bruni (1370-1444); y el último, por haberse servido de un estudio perdido sobre la Poética, previo a toda edición de la misma (en 1480) y hecho por un sobrino de otro discípulo de Crisoloras que llegó a ser su yerno, Ermolao Barbaro (1454-1493).

Alberti, por otra parte, como autor de tres tratados sobre plástica y arquitectura, es bien conocido entre los historiadores del arte. En este campo es sabido, por autores como Gombrich, que al menos en dos de sus obras este teórico renacentista incluyó alusiones más o menos literales a la Poética aristotélica. Tomando en cuenta que la primera de ellas, De pintura, fue redactada en 1435 y la otra, De arquitectura, entre 1443 y 1452, hay que notar que la más antigua es anterior a la invención de la imprenta y que, por ende, precede casi setenta años a la primera edición de la Poética. Ahora bien, como De arquitectura fue editada por primera vez en 1485, resulta que es la portadora de la referencia impresa más antigua que existe del tratado, y como fue prologada precisamente por Poliziano y dedicada a Lorenzo de Medici, el tratado aristotélico sobre poesía parece haber tenido un influjo definitivo, aunque sutil, a través de la Academia platónica florentina.

Particularmente destacable es que Crisoloras orienta la atención hacia la plástica al difundir el tratado; lo hace centrándose, ante todo, en la parte inicial, donde se explica que la labor creativa humana en general tiene un mismo origen, la mímesis; Alberti, manteniéndose fiel a esa orientación visual y a dicha idea de unidad original del arte, procura completar lo que el propio Aristóteles parece anunciar en su texto y dejar inconcluso, sin llegar a hacerlo por completo. 
La amplitud originaria de la noción de poesía que Aristóteles reconoce y que permea el título que se dio al tratado, apunta a un tratamiento de todas las artes que a la larga habrían de constituirse como bellas artes, en vez de circunscribirlo al campo de la literatura y menos a un género particular, el trágico, que, no obstante, acabó siendo el contenido esencial de la obra. Como Alberti pudo haber identificado esta discrepancia entre contenido y nombre en la obra, parece haber tomado la Poética como un proyecto incompleto y asumido voluntariamente la tarea de proseguirlo allende la literatura, a pesar de no haber dedicado, él tampoco, atención cabal ni a la música ni a la danza, y a pesar también de que Aristóteles omite toda alusión a la arquitectura en su tratado sobre la creación artística-mientras que Alberti le da un lugar primordial, siguiendo a Vitrubio.

Ciertamente, esta precisión sobre la Poética como proyecto trunco parece traernos de vuelta al supuesto extravío de la segunda parte de la Poética. En todo caso, lo que aquí sacamos a la luz colinda más bien, por complemento, con la insistencia nietzscheana en volver a la comprensión de la importancia de la música y el movimiento escénico como partes de la tragedia, y en la visión del artista trágico como análogo al atleta maratónico, diestro en múltiples disciplinas. ${ }^{6}$ No sólo porque semejante hombre se aproxima, en cierto sentido, a la idea más común de hombre en el Renacimiento; también porque - dada la inclusión de la música y la coreografía dramática entre los elementos del arte trágico, según el propio Aristóteles, $\mathrm{y}$, pese a la irreductibilidad de estas dos manifestaciones miméticas al drama- las parcelas artísticas más ajenas al único género creativo desarrollado por Aristóteles en el tratado de poesía son, justamente, aquellas sobre las que Alberti trató.

Por último, como eslabón final de la recepción del tratado aristotélico en el Renacimiento, retomaré el tema del Concilio de Trento. En primer lugar, cabe observar la proximidad entre el pasaje tridentino donde se retoman resoluciones del segundo Concilio Niceno (787) y el pasaje de la Poética que alude igualmente a la mímesis icónica como

${ }^{6}$ Friedrich Nietzsche, "El drama musical griego", escrito preparatorio a El nacimiento de la tragedia o Grecia y el pesimismo, 1973, Madrid, Alianza editorial, trad. de Andrés Sánchez Pascual, pp. 195-212. 
medio de aprendizaje y goce. A fin de promover y defender las imágenes como un medio idóneo de enseñanza, por la excitación de la sensibilidad que pueden suscitar, el primero dice: "el honor que se da a las imágenes, se refiere a los originales representados en ellas". ${ }^{7}$ Por su parte, sobre el mismo tipo de representaciones visuales, el segundo dice en el fragmento que Crisoloras solía citar: "al contemplarlas, aprenden y deducen qué es cada cosa, por ejemplo, que éste es aquél.” De suerte que en ambos encontramos enfatizado el ser de lo referido a costa del ser del referente.

Sin embargo, más significativa que esta relación entre citas es la presencia de múltiples conceptos y expresiones importantes de la Poética, constelados a lo largo de los tres párrafos que integran los acuerdos de esta sesión conciliar. Me limito a mostrar el siguiente fragmento:

Enseñen con esmero los obispos que por medio de las historias de nuestra redención, expresadas en pinturas y otras copias, se instruye y confirma el pueblo recordándoles los artículos de la fe, y recapacitándoles continuamente en ellos: además que se saca mucho fruto de todas las sagradas imágenes, no sólo porque recuerdan al pueblo los beneficios y dones que Cristo les ha concedido, sino también porque se exponen a los ojos de los fieles los saludables ejemplos de los santos, y los milagros que Dios ha obrado por ellos, con el fin de que den gracias a Dios por ellos, y arreglen su vida y costumbres a los ejemplos de los mismos santos; así como para que se exciten a adorar, y amar a Dios, y practicar la piedad. ${ }^{8}$

Por principio, la noción de "copia" es evidentemente un correlato de la de mímesis; la alusión a las historias es correlativa a la de mito o trama de la acción en la Poética. La expresión "exponer a los ojos" es frecuente en el texto aristotélico, apunta a una comprensión particular griega de visibilidad, asociada por un lado a la contemplación interior

7 "De la invocación, veneración y reliquias de los Santos, y de las sagradas imágenes", El sacrosanto y ecuménico concilio de Trento, traducido al idioma catellano por don Ignacio López de Ayala, M.DCCLXXXVII, Madrid, Imprenta Real, p. 358. [http://132.248.9.32:8080/ fondoantiguo1/1205549-652094/JPEG/Index.html]

${ }^{8}$ Ibid., p. 358. 
o teorética, más que a la percepción directa, y por otro, a la capacidad de otorgar una forma sensible a lo meramente imaginado o visto interiormente, que es, por supuesto, una labor poética; en última instancia, el nudo entre el tramar y el "poner ante los ojos" apunta a una especie de convergencia entre el teatro y la plástica.

Centrándonos en la plástica, cabe observar que esa convergencia es justamente el nicho en que se inscribe la iconografía cristiana en general, dada su base en relatos sobre la vida de Jesús y los santos. Han de evidenciarse otros dos rasgos de esta clase de producción icónica, en los que se insiste en este concilio, por su destacado puesto dentro de la Poética. Me refiero a las nociones de "piedad" y "redención". La primera, en el ámbito griego se entiende como compasión (éleos), y se inscribe en el campo de lo patético, mientras que la segunda se vincula con la catarsis, en la medida en que puede entenderse como liberación, al igual que la salvación.

Pese a que esta convergencia entre aspectos típicos del drama trágico y de la plástica cristiana data más bien de la Edad media, y el Concilio de Trento no hace más que revitalizarlos, son notables tanto la orientación pragmática que finalmente adquirió el redescubrimiento de la Poética, como el desplazamiento en la interpretación de este tratado hacia lo icónico. En buena medida, ese giro provino de la coyuntura por la que algo de la valoración bizantina de los íconos permeó la formación de los primeros humanistas, debido al origen euroriental de figuras como Crisoloras.

Independientemente de que el encuentro renacentista de esta fuente haya permitido una mejor comprensión de su contenido, particularmente por lo que atañe al teatro, a la larga los primeros europeos modernos también se abocaron a entender y a usar la Poética a partir de los requerimientos de su propio contexto artístico y religioso, por lo cual una crítica a la recepción arábiga de este tratado, por haber hecho algo análogo, resulta vulnerable.

Es importante no perder de vista que, a pesar de que la reconquista implica precisamente un repliegue de la correlación entre la cultura árabe y la hispánica, precisamente durante el período de dominación 
arábiga de la península tiene esta cultura su propio encuentro de la Poética. De suerte que sondear la posibilidad de que por esta vía, antes incluso que por el influjo del Renacimiento, algunos aspectos de la Poética hayan podido incidir sobre el campo de la literatura española es una tarea atractiva. En la sesión dedicada a las imágenes, el papel de los españoles fue definitivo, ya que fueron ellos quienes propusieron tratar la cuestión misma; como el cierre del evento resultó precipitado, a pesar de que algunas cuestiones previstas no llegaron a ser tratadas, ésta, que originalmente no lo fuera, logró ser atendida. ${ }^{9}$

Considerando que esto ocurrió en 1564, cuando Nueva España estaba por cumplir treinta años de haberse constituido como virreinato, resulta bien comprensible que para los españoles fuera especialmente importante el tema de la enseñanza y la reafirmación de la fe cristiana por medios icónicos, ante la gran empresa de evangelización que se encontraban desempeñando, ante una población ajena a su lengua pero receptiva al aprendizaje mediante imágenes, debido a la existencia previa de los llamados códices americanos; no obstante, ello por supuesto no implica negar que en este Concilio el tratamiento de la temática de las imágenes, aunado a la de las reliquias y los santos, respondía además a diversas posturas cristianas no católicas.

Por otro lado, el enfoque particular de esta cuestión en relación con la Poética remite al peso que había ganado la filosofía humanística aristotélica en el ámbito eclesiástico español; no se olvide que el Concilio se extendió casi veinte años y considérese que, desde el inicio, esta tendencia aristotélica definió el carácter de los partícipes de la península ibérica, pues precisamente un antepasado Gonzáles de Mendoza, quien estuvo presente más bien al inicio del evento, se dice que llegó a fundar una especie de Academia aristotélica, en contraposición y en deuda con la conocida Academia platónica florentina: fue Diego Hurtado de Mendoza y su genealogía ha de interesarnos, más allá del concilio, porque fue a uno de sus hermanos a quien se le otorgó el privilegio y la responsabilidad de regir, por primera vez, como Virrey en Nueva España.

${ }^{9}$ Pedro González de Mendoza, El Concilio de Trento (Memoria de lo sucedido en), 1970, Madrid, Espasa-Calpe, pp. 147-52. 


\section{El primer virrey novohispano y las primeras repercusiones de la Poética en América}

Si resulta aceptable la propuesta esbozada de que la Poética es, de manera indirecta, una de las fuentes principales que sustenta la sesión tridentina sobre las imágenes, entonces es admisible también que la repercusión de este tratado en la iconografía novohispana, desde fines del siglo XVI, puede entenderse como un vasto ámbito de recepción mediata; análogas repercusiones pueden reconocerse en otros ámbitos culturales desde la época del primer virrey novohispano, Antonio de Mendoza.

Guillermo Tovar de Teresa sostiene que de Mendoza puede considerarse, hasta cierto punto, como un arquitecto y que, con base en el tratado de Alberti sobre esta materia, él intervino en el trazo urbano de la Ciudad de México. En torno a este planteamiento existe debate, en tanto autores como Sánchez Carmona lo cuestionan: ${ }^{10}$ no obstante, al menos el hallazgo por parte del mismo Tovar de anotaciones como: "de Antonio de Mendoza visorrey", ${ }^{11}$ realizadas sobre una edición del tratado mencionado hacia 1539, permite hablar de una injerencia indirecta de la Poética por esta vía, si se acepta la propuesta de considerar los tratados de este autor como una especie de continuaciones de la Poética.

Rotundamente, desde la portada y en el título original, la obra atribuida a Jerónimo de Alcalá y llamada por abreviatura Relación de Michoacán tiene por destinatario a Antonio de Mendoza; en su prólogo, abundan referencias a las virtudes de este gobernante y destaca cierta correspondencia entre su primera línea y un planteamiento implícito del capítulo IV, frecuentemente aludido.

Explicando su interés por recabar la información contenida en su relación, de Alcalá comienza apelando a una máxima popular sobre el conocimiento humano, conforme a la cual todos, por naturaleza, lo

${ }^{10}$ Manuel Sánchez Carmona, en Las ciudades del encuentro, 1992, México, UAM-LimusaNoriega, p. 72.

${ }^{11}$ Guillermo Tovar de Teresa, "La utopía del virrey de Mendoza", La utopía mexicana del siglo XVI. Lo bello, lo verdadero y lo bueno, 1992, México, Azabache, p. 19. 
buscamos. Sus palabras son éstas: "Es un dicho muy común que dice: que naturalmente buscan todos el saber". ${ }^{12}$ No hemos de problematizar ahora el proceso implícito en la popularización de esta idea; simplemente queremos hacer notar su presencia en la Poética.

El capítulo mencionado inicia justamente con nuestra primera forma de conocer, la imitación, tendencia humana natural; el principal destinatario del códice michoacano, Antonio de Mendoza, es además el promotor del saber recogido en la obra de Alcalá, y considerando también el carácter mimético de la relación, dado su contenido pictórico, cabe insistir en el perfil de mecenas renacentista que Robertson supo reconocer en Mendoza. ${ }^{13} \mathrm{Y}$ es curioso que uno de los primeros historiadores del arte que se interesaron por el contenido pictórico de la obra de Alcalá, Manuel Toussaint, haya parafraseado la Poética al apreciarlas, pues tras haber destacado su belleza y otras cualidades estéticas, como la vitalidad, agrega: "Nada hay sobrante, todo es necesario". ${ }^{14}$

En parte, esto se explica por la formación que el Virrey recibió en Granada del humanista Pedro Mártir de Angelaría, junto con algunos otros nobles de su familia y de otras estirpes, pero también parte integral de la formación de la nobleza se cifraba en la poesía y no sólo su hermano Diego destacó en este campo, sino sobre todo su abuelo, el célebre Marqués de Santillana. De suerte que incluso algunos de sus planteamientos expresados en La carta-proemio al condestable de Portugal, como su definición de poesía en términos de fingimiento, su distinción entre poesía sublime, mediocre y vulgar, y su breve recuento histórico de la literatura, sin precedentes en España, pueden valorarse en relación con la Poética aristotélica por otra vía, aunque menos directa aun, por tratarse de un autor de transición entre el medioevo y el Renacimiento temprano.

${ }^{12}$ Jerónimo de Alcalá, Relación de las ceremonias y rictos y población y gobernación de los indios de la provincia de Michoacán, 2000, Zamora, Gobierno del Estado de MichoacánColegio de Michoacán, p. 326.

${ }^{13}$ Donald Robertson, Mexican Manuscript Painting of the Early Colonial Period: The Metropolitan Schools, 1959, New Haven, University of Yale Press, p. 46.

${ }^{14}$ Manuel Toussaint, "La relación de Michoacán. Su importancia artística", Anales del Instituto de Investigaciones Estéticas, 1937, vol. 1, p. 11. 
No obstante, su cercanía relativa a aristotélicos proto-humanistas de su tiempo, como Cartagena y Bruni, parece haber allanado el terreno al futuro proyecto de su nieto Diego: academizar este tipo de estudios filosóficos. Legando a sus familiares una vasta biblioteca con obras latinas, castellanas, toscanas y francesas, el marqués ensanchó su interés por otras culturas, de suerte que sus descendientes, como hombres de letras y caballeros en la etapa final de la reconquista, comienzan también a familiarizare con las textos árabes y a adquirirlos, interesándose además en aprender la lengua.

Esta apertura al intercambio cultural con una cultura sometida será decisiva para la elección de Antonio de Mendoza, y su particular incidencia en la producción de códices - como el mendocino en especial, además de la Relación de Michoacán-se entiende así en términos de continuidad. A lo largo de toda esta vena genealógica puede decirse que el humanismo de corte aristotélico, con la Poética como uno de los componentes esenciales, constituyó un flujo constante y en transformación continua, por el contacto con contextos nuevos, cual la Nueva España. 